matters arising

\section{Improved amorphous semiconductors for solar cells}

OVSHINSKY AND MADAN ${ }^{1}$ have described the interesting results of incorporating fluorine in glow discharge deposited amorphous silicon (in particular a very low density of states within the gap.) However, as one would expect on general grounds, fluorinated material has a significantly larger energy gap than hydrogenated material. It therefore offers an even less good match to the solar spectrum, which would not improve the efficiency of solar cells made from it. Although the use of iodine rather than fluorine might be expected to be helpful in this respect it is still unlikely to reduce the energy gap to the near $1 \mathrm{eV}$ value required for optimum spectral response. [The stability of the $\mathrm{Si}-\mathrm{I}$ bond shown by the surface stabilisation of silicon by iodine ${ }^{2}$, led me to discuss the possible use of iodine in glow discharge deposited silicon with several workers at the International Conference on the Physics of Semiconductors at Edinburgh in September 1979.]

During our group's early work on glow discharge deposition of amorphous materials (see refs 3,4 ) it was observed that germanium and silicon-germanium alloys deposited by glow discharge from germane or germane-silane mixtures, even with rather small germanium content, show negligible photoconductivity compared with pure silicon. This would now be interpreted in terms of the $\mathrm{Ge}-\mathrm{H}$ bond being weak compared with the $\mathrm{Si}-\mathrm{H}$ bond, with the result that dangling bonds on germanium atoms are not stably hydrogenated in amorphous germanium and its alloys, and with the further consequence that these materials have a large density of states in the gap. It would therefore not be possible to prepare solar cells from them even though their absorption edge could be well matched to the solar spectrum. Clearly this situation would alter if a stronger bonding element, such as a halogen, were used to satisfy germanium dangling bonds. (Even the Ge-I bond is far more stable than $\mathrm{Ge}-\mathrm{H}$ ). What is suggested, then, is that particularly promising amorphous semiconductors for making efficient solar cells would be germanium and $\mathrm{Ge}$ Si alloys incorporating halogen, the overall composition tailored to optimise the photoconductive response spectrum to solar radiation.
Note added in proof: The optimum energy gap for matching a cell to the AM1 solar spectrum is about $1.4 \mathrm{eV}$ (see, for example, ref. 5). However, even at the Equator the Sun is not long at the zenith (implied by AM1), and the increasing atmospheric absorption at lower solar angles characteristic of most of the day (all of it at higher latitudes, outside the tropics) shifts the optimum energy gap to still lower values. It would only be with high temperature operation (above $-300^{\circ} \mathrm{C}$ ) that fluorinated amorphous silicon could be considered to provide a good spectral match. As the main aim in developing large area solar cells is to avoid concentration of radiation, the maximum temperature likely to be encountered with them is perhaps $65^{\circ} \mathrm{C}$.

\section{H. L. GOODMAN \\ Standard Telecommunication \\ Laboratories, \\ London Road, \\ Harlow, Essex, UK}

1. Ovshinsky, S. R. \& Madan, A. Nature 276, 482 (1978). 2. Lieberman, R. \& Klein, D. L. J. Electrochem. Soc. 113, 956-8 (1966).

3. Stering, H. F. \& Swann, R. C. G. Phys. Chem. Glasses 6 , 109 (1965)

4. Chittick, R. C., Alexander, J. H. \& Sterling, H. F. J. electrochem. Soc. 116, 77-81 (1969)

5. Loterski, J. J. J. appl. Phys. 27, 777 (1956)

OVSHINSKY AND MADAN REPLYGoodman suggests that (1) the optimal energy gap for solar photovoltaic energy conversion is $1 \mathrm{eV}$ and (2) fluorinated amorphous silicon has a significantly larger energy gap than hydrogenated amorphous silicon, and thus concludes that amorphous germanium or $\mathrm{Ge}-\mathrm{Si}$ alloys are preferential to amorphous silicon for solar-cell applications. Both of the above premises are incorrect.

It is well known ${ }^{1,2}$ that the optimal gap for solar photovoltaic energy conversion is about $1.6 \mathrm{eV}$, not $1 \mathrm{eV}$. For example, the maximum efficiency for Am-0 using a semiconductor with an energy gap of $1.6 \mathrm{eV}$ is about $25 \%$, more than half again as large as the $16 \%$ maximum efficiency of a material with a $1.0 \mathrm{eV}$ gap $^{3}$. Furthermore, the energy gap of our new amorphous $\mathrm{Si}: \mathrm{F}: \mathrm{H}$ alloy is determined by a Fowler plot and clearly stated in our letter ${ }^{4}$ is $1.65 \mathrm{eV}$, which is essentially the optimal value. In fact, it is not significantly different from the energy gaps of 1.55$1.8 \mathrm{eV}$ obtained in silane-decomposed films $s^{5.6}$, nor is it much larger than the $1.5 \mathrm{eV}$ gap of nominally pure amorphous silicon $^{7,8}$. The reason for this is that the fluorine concentration of the new alloy is $<5 \%$ and thus the vast majority of the chemical bonds that determine the energy gap of the material are ordinary $\mathrm{Si}-\mathrm{Si}$ covalent bonds.

The major purpose of our letter ${ }^{4}$ was to point out that the new alloy has many features in addition to its band gap that makes it more desirable than silanedecomposed material for solar-cell applications.

Note added in proof: Goodman in his note in proof now suggests that higher air-mass conditions would greatly deteriorate the performance of amorphous $\mathrm{Si}: \mathrm{F}: \mathrm{H}$ solar cells on the basis of a $1.65-\mathrm{eV}$ gap. The facts are as follows ${ }^{9}$. At AM-2, when the sunlight is at an angle of $60^{\circ}$ to the Earth's surface (approximately the spectrum for average, slightly hazy weather conditions and smaller sun angles, as in temperatezone climates), the maximum conversion efficiency of an ordinary solar cell is $\sim 26 \%$. For a gap of $1.65 \mathrm{eV}$, the maximum conversion efficiency is still $25 \%$. This figure, in fact, is larger than the maximum conversion efficiency at any energy gap for AM-0 conditions (because of the decrease in relative solar irradiance in the near infrared at AM-2). The main point is that the maximum conversion efficiency is only a weak function of energy gap in the 1.0-2.0 eV range (never dropping below $20 \%$ in this range at AM-2), so that the efficiencies of real devices are much more dependent on other parameters.

\section{S. R. OVSHINSKY}

A. MADAN

Energy Conversion Devices, Inc., 1675 West Maple Road,

Troy, Michigan 48084

1. Loferski, J. J. J. Appl. Phys 27, 777 (1956)

2. Hovel, H. J. Solar Cells, 72 (Academic, New York, 1975)

3. Angrist, S. W. Direct Energy Conversion, 2nd edn, 211 (Allyn and Bacon, Boston, 1974).

4. Ovshinsky, S. R. \& Madan, A. Nature 276, 482 (1978)

5. Loveland, R. J., Spear, W. E. \& Al-Sharbary, A. J. Non Cryst. Solids 13, 55 (1973/1974).

6. Carlson, D. E. \& Wronski, C. R. J. Electr. Mater. 6, 95 (1977)

7. Mizrah, T. \& Adler, D., IEEE Trans. ED-24, $458(1977)$

8. Adler, D., et al. J. Non-Cryst. Solids 8-10, 844 (1972).

9. Hovel, H. J. Solar Cells, 75 (Academic, New York, 1975).

\section{Asbestos-enhanced uptake of carcinogens}

THE results of Lakowicz and Hylden's studies $^{1}$ on asbestos-mediated uptake of benzo( $a$ )pyrene (BP) by dipalmitoyl L- $\alpha$ phosphatidylcholine (DPPC) vesicles are more indicative of in vivo transfer of $\mathrm{BP}$ from particulates to lung surfactant (mainly DPPC and other phospholipids ${ }^{2}$ ) 